\title{
Creep Behavior and Life Assessment of a Novel Heat-Resistant Austenite Steel and Its Weldment
}

\author{
Yu Zhang ${ }^{1,2} \cdot$ Hong-Yang Jing ${ }^{1,2} \cdot$ Lian-Yong Xu ${ }^{1,2} \cdot$ Yong-Dian Han ${ }^{1,2} \cdot$ Lei Zhao ${ }^{1,2} \cdot \mathrm{Xi}^{-S h a n} \mathrm{Xie}^{3} \cdot$ \\ Qiu-Hua Zhu ${ }^{4}$
}

Received: 2 May 2018/Revised: 9 July 2018/Published online: 27 September 2018

(C) The Chinese Society for Metals and Springer-Verlag GmbH Germany, part of Springer Nature 2018

\begin{abstract}
In the present study, creep activation energy for rupture was obtained as $221-348 \mathrm{~kJ} / \mathrm{mol}$ for $22 \mathrm{Cr} 15 \mathrm{Ni} 3.5 \mathrm{CuNbN}$ due to the precipitation-hardening mechanism. The extrapolation strength of creep rupture time of $10^{5} \mathrm{~h}$ at $923 \mathrm{~K}$ for $22 \mathrm{Cr} 15 \mathrm{Ni} 3.5 \mathrm{CuNbN}$ is more valid $(83.71 \mathrm{MPa})$ predicted by the Manson-Haferd method, which is superior to other commercial heat-resistant steels. The tensile creep tests ranging from 180 to $240 \mathrm{MPa}$ at $923 \mathrm{~K}$ were conducted to investigate creep deformation behavior of welded joint between a novel heat-resistant austenite steel $22 \mathrm{Cr} 15 \mathrm{Ni} 3.5 \mathrm{CuNbN}$ and ERNiCrCoMo-1 weld metal. Apparent stress exponent value of 6.54 was obtained, which indicated that the ratecontrolled creep occurred in weldment during creep. A damage tolerance factor of 6.4 in the weldment illustrates that the microstructural degradation is the dominant creep damaging mechanism in the alloy. Meanwhile, the welded joints perform two types of deformation behavior with the variation in applied stress, which resulted from the different parts that govern the creep processing. Also, the morphology evolution of the fracture surfaces confirms the effects of stress level and stress state.
\end{abstract}

Keywords Heat-resistant steel weldment · Creep deformation · Life assessment · TTP (time-temperature parametric) method

\section{Introduction}

A greater emphasis has been placed on ultra-supercritical (USC) generation technology with elevated operating parameters and higher heat efficiency in order to solve the energy crisis and mitigate global warming [1-3]. Recently, considerable studies have been conducted on developing materials that adapts to USC power plant with operating

Available online at http://link.springer.com/journal/40195

Lian-Yong Xu

xulianyong@tju.edu.cn

1 School of Materials Science and Engineering, Tianjin University, Tianjin 300350, China

2 Tianjin Key Laboratory of Advanced Joining Technology, Tianjin 300350, China

3 School of Materials Science and Engineering, University of Science and Technology, Beijing, Beijing 100083, China

4 Jiangsu Wujin Stainless Steel Pipe Group Co., Ltd, Changzhou 213111, China temperatures of around $650-700{ }^{\circ} \mathrm{C}$ [4-6]. Nevertheless, considering the scarcity of materials available, the $630-650{ }^{\circ} \mathrm{C}$ USC technology is currently a bottleneck among USC power generation technologies. Against this background, a novel austenitic heat-resistant steel, 22Cr15Ni3.5CuNbN (SP2215), was developed for using in the super-/reheaters of $650{ }^{\circ} \mathrm{C}$ USC plants due to its sufficient creep strength, least reduction in toughness while in service, and lower consumption of chromium and nickel $[7,8]$. The prerequisite for determining lives of long-term service for high-temperature components and structures has been addressed for more than 50 years through the application of time-temperature parametric (TTP) equations. The TTP equations collapse data obtained over a variety of temperatures and exposure times onto a single relationship. Recent researches on life assessment of high-temperature alloys used in power plants, nevertheless, mainly converge on grades 91 and 92 [9-13]. The long-term lifetime extrapolation and allowable stress calculation are particularly inadequate for newly developed high-temperature steel. Meanwhile, welding is an inevitable processing 
utilized in assembling super-/reheaters when constructing USC plants. Studies on creep deformation behavior of austenitic heat-resistant steel weldments appear to be deficient in light of reviews on weld performance of candidate austenitic and alloys for advanced ultra-supercritical fossil power plants $[14,15]$. Hence, investigation on life assessment of the $22 \mathrm{Cr} 15 \mathrm{Ni} 3.5 \mathrm{CuNbN}$ heat-resistant steels and creep behavior of its welded joints has become a significant importance in the successful operation of $630-650{ }^{\circ} \mathrm{C}$ USC plants.

In this study, tensile creep tests of the $22 \mathrm{Cr} 15 \mathrm{Ni} 3.5$ $\mathrm{CuNbN}$ welded joints were conducted at $923 \mathrm{~K}$. Creep life was assessed and predicted for the heat-resistant steel via different methods based on massive volume of creep rupture data obtained from the tube producer. Creep behaviors of the weldment were analyzed by using a creep tolerance factor. The relevant creep fracture surfaces were observed, and comparative studies between various stress levels were made. Furthermore, the finding in creep power law between the base metal and weldment were interpreted in the view of creep ductility.

\section{Materials and Methods}

In the present work, $22 \mathrm{Cr} 15 \mathrm{Ni} 3.5 \mathrm{CuNbN}$ was received as solution annealed (922-1523 K) seamless tube. Manual gas tungsten arc welding (GTAW) was used to form the joint with $100 \%$ argon shielding and ERNiCrCoMo-1 wire filling $(\varphi 2.4 \mathrm{~mm})$. Specifications of the tube and welding parameters are shown in Table 1. Preheating and post-weld heat treatment were not applied in welding the steel. Figure 1 presents the photograph of the welded joint. Nondestructive testing (NDT) demonstrates that there are no welding defects in the weldment. Table 2 shows the measured chemical compositions of $22 \mathrm{Cr} 15 \mathrm{Ni} 3.5 \mathrm{CuNbN}$ base metal (BM) and ERNiCrCoMo-1 weld metal (WM). Round tensile creep specimens were machined parallel to the axial direction of the tubes, shown in Fig. 1. The uniaxial tensile creep tests were conducted in atmosphere at $923 \mathrm{~K}$ under four stress levels $(180,200,220$, and $240 \mathrm{MPa})$ by using a leveraged creep machine (CRIMS RDJ50) with a hightemperature furnace. For tensile creep experiment, three $\mathrm{K}$-thermocouples were attached to the specimen to monitor and regulate the test temperature. Double linear variable displacement transducer (LVDT) extensometers were used to measure gage length displacement and record the

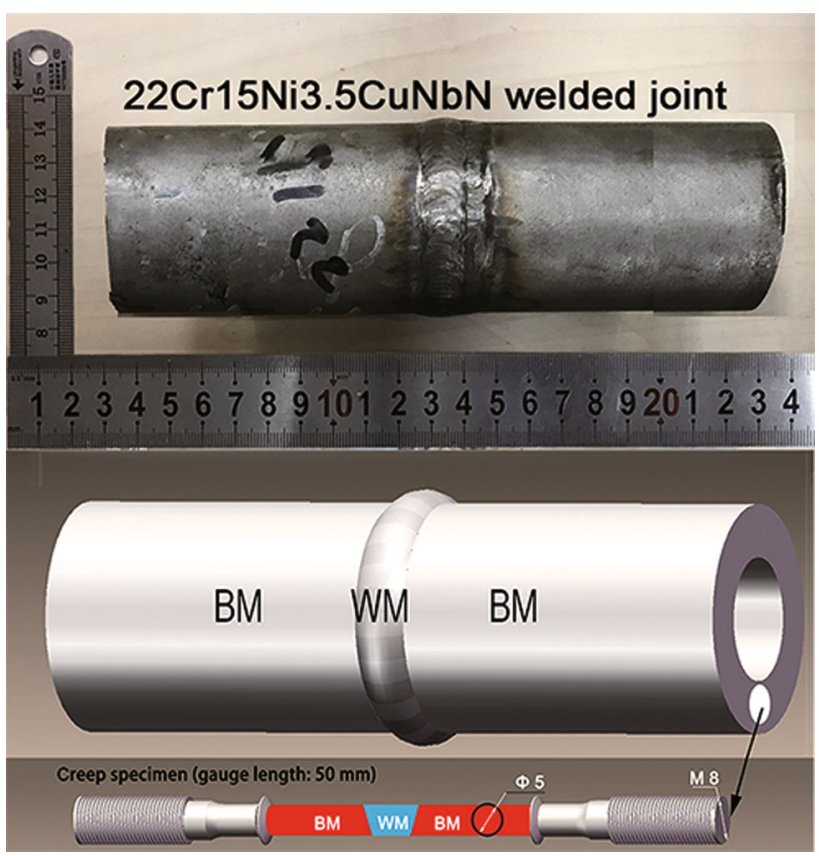

Fig. $122 \mathrm{Cr} 15 \mathrm{Ni} 3.5 \mathrm{CuNbN}$ weldment and the schematic representation of the sampling location for creep strain tests

cumulative creep strain for each sample. The resolutions of furnace temperature and LVDT extensometers were $0.1 \mathrm{~K}$ and $0.001 \mathrm{~mm}$, respectively. It is noted that using K-type thermocouple may cause early deterioration and long-term deterioration problems, decreasing in thermoelectromotive force with increasing time, which results in unsafe creep rupture data. The gage length and cross-sectional area of each specimen were measured before and after creep testing to estimate percentages of elongation and reduction in area. Scanning electron microscopy (SEM, FEI Nanosem 430) was used to examine the fracture surfaces.

\section{Results and Discussion}

\subsection{Creep Rupture Exponent and Activation Energy}

Creep lifetime and ductility data of the steel at a variety of temperatures and applied stress from third-party research institutions were provided by the seamless tube manufacturer. The data labeled with abbreviation of "SH" were acquired from Shanghai Power Equipment Research Institute, China, and the data labeled with the "SZ" were
Table 1 Chemical compositions $9 \mathrm{wt} \%$ of $22 \mathrm{Cr} 15 \mathrm{Ni} 3.5 \mathrm{CuNbN}$ (BM) and weld metal (WM)

\begin{tabular}{lllllllllllllll}
\hline Material & $\mathrm{C}$ & $\mathrm{Si}$ & $\mathrm{Mn}$ & $\mathrm{Cr}$ & $\mathrm{Ni}$ & $\mathrm{Mo}$ & $\mathrm{Cu}$ & $\mathrm{Co}$ & $\mathrm{W}$ & $\mathrm{Nb}$ & $\mathrm{Ti}$ & $\mathrm{N}$ & $\mathrm{Fe}$ \\
\hline $\mathrm{BM}$ & 0.07 & 0.38 & 0.64 & 22.6 & 15.7 & 0.12 & 3.5 & 0.06 & 0.008 & 0.53 & 0.006 & 0.34 & 56.03 \\
$\mathrm{WM}$ & 0.065 & 0.11 & 0.12 & 21.92 & 47.89 & 7.1 & 0.94 & 8.38 & 0.27 & 0.11 & 0.31 & 0.044 & 13.04 \\
\hline
\end{tabular}


Table 2 Specifications of the tubes and the welding parameters

\begin{tabular}{lllllll}
\hline Material & $\begin{array}{l}\text { Outside diameter } \\
(\mathrm{mm})\end{array}$ & $\begin{array}{l}\text { Wall thickness } \\
(\mathrm{mm})\end{array}$ & $\begin{array}{l}\text { Welding current } \\
(\mathrm{A})\end{array}$ & $\begin{array}{l}\text { Welding voltage } \\
(\mathrm{V})\end{array}$ & $\begin{array}{l}\text { Interpass temperature } \\
\left({ }^{\circ} \mathrm{C}\right)\end{array}$ & $\begin{array}{l}\text { Groove angle } \\
\left({ }^{\circ}\right)\end{array}$ \\
\hline $22 \mathrm{Cr} 15 \mathrm{Ni3} .5 \mathrm{CuNbN}$ & 51.0 & 10.3 & $90-120$ & $10-15$ & 100 & 70 \\
\hline
\end{tabular}

acquired from Suzhou Nuclear Power Research Institute, China. Besides, the data labeled with abbreviation of "TD" were derived from the present study. The information was used to calculate and evaluate the life expectancy of the heat-resistant steel and its weldment.

\subsubsection{Creep Rupture Exponent of the Steel and Weldment}

Variations between applied stress $\left(t_{\mathrm{r}}\right)$ and creep life $\left(\sigma_{a}\right)$ of the $\mathrm{BM}$ at different temperatures are logarithmically plotted in Fig. 2 in the format of $t_{\mathrm{r}}=A_{1} \sigma_{a}^{-n_{1}}$, where $A_{1}$ is a coefficient and $n_{1}$ is creep rupture exponent. The decline in creep rupture exponent with increasing tested temperature exhibits a microstructural degradation such as coarsening of the carbides and formation of subgrains [2]. It is noted that the creep rupture exponent for the BM at $1023 \mathrm{~K}$ is not in conformity to the above rule, which may be attributed to the dispersiveness and fortuity of the creep data at $1023 \mathrm{~K}$.

Furthermore, variations between applied stress and creep life at $923 \mathrm{~K}$ of the $\mathrm{BM}$, welded joint, and IN alloy 617 are depicted in a $\log -\log$ coordinate as shown in Fig. 3, where an intersection point occurred between the fitting curves of the $\mathrm{BM}$ and the joint. The stress value at the intersection is very close to the yield stress of the BM at $923 \mathrm{~K}$. A large quantity of the exponent is considered to represent a great deformation-resistance capacity of the material during creep. Given that the IN 617 has a greater

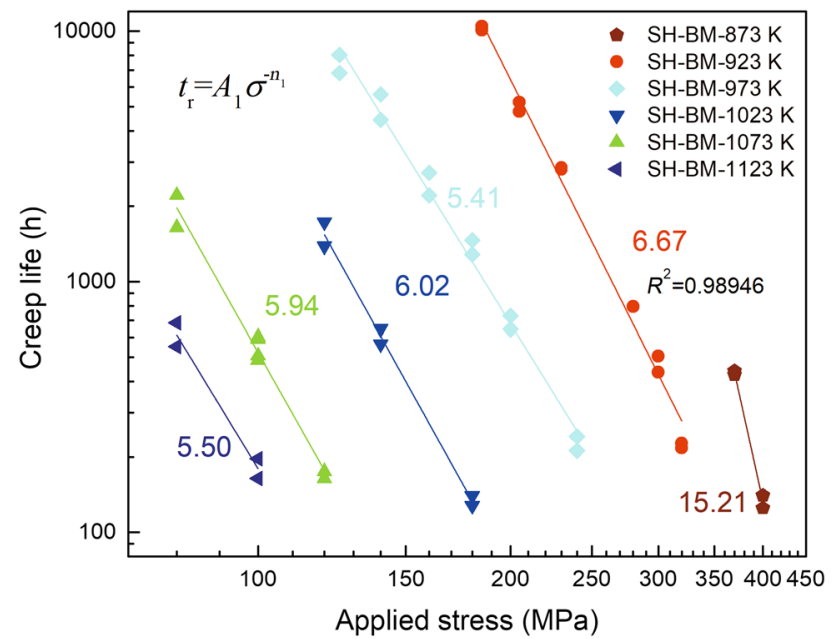

Fig. 2 Variations between creep lifetime and applied stress at different temperatures

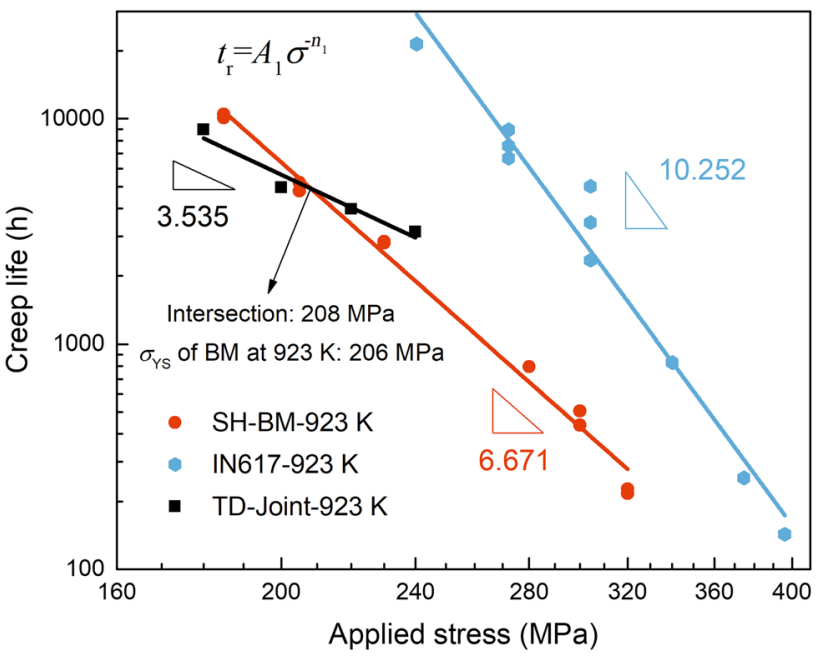

Fig. 3 Variations between creep lifetime and applied stress at $923 \mathrm{~K}$

creep rupture exponent value (over ten), the welded joint is bound to behave a comprehensive creep resistance due to the presence of compatible creep deformation behavior including the $\mathrm{BM}$ and the WM. To confirm this finding, creep life data at $973 \mathrm{~K}$ of the $\mathrm{BM}$ and weldment are plotted in a bilogarithmic graph (Fig. 4), where the two fitting curves meet at the applied stress of $179 \mathrm{MPa}$, which is roughly equal to the yield stress of the $\mathrm{BM}$ at $973 \mathrm{~K}$. The phenomenon can be illustrated by introducing the concept of creep strain to failure (creep ductility). The variations of

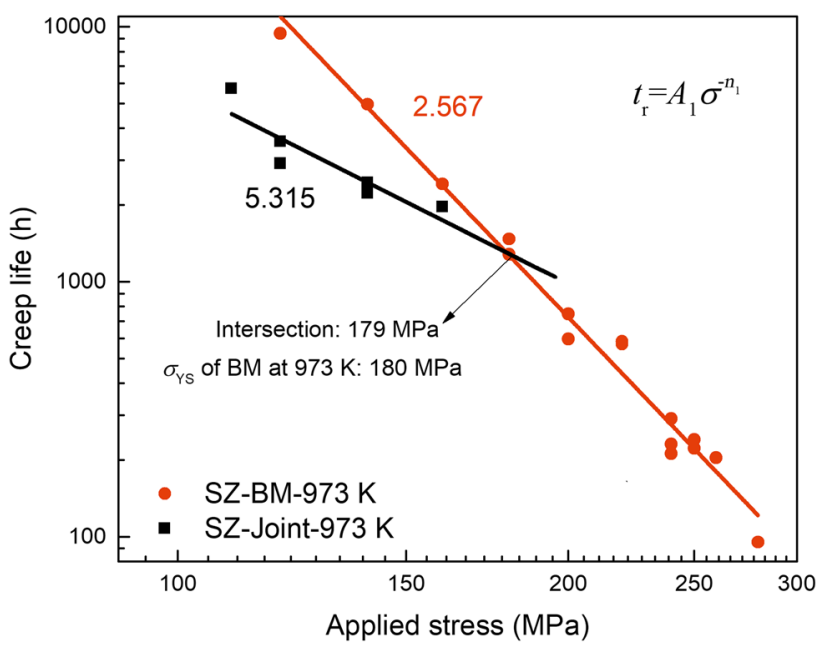

Fig. 4 Variations between creep lifetime and applied stress at $973 \mathrm{~K}$ 
creep ductility (strain to failure and area reduction) versus applied stress of the BM and weldment after creep at $923 \mathrm{~K}$ are shown in Fig. 5, where the BM and weldment exhibit approximated quantities of creep ductility under applied stress below $200 \mathrm{MPa}$, while the creep ductility of the welded joint becomes much lower than that of the BM when stress beyond $200 \mathrm{MPa}$ is applied. This is to say, whether the applied stress surpasses the yielding limit of the BM significantly influences the trend of creep lifetime of welded joint. Considering the situation that creep stress level is lower than the yield limit of the BM (and obviously lower than the weldment) at a given temperature, the WM can be regarded as a rigid body, and thus the creep life of the weldment is mainly controlled by the BM. When applied stress level exceeds the yield limit of BM, on the other hand, creep life is mainly confined to the combination effect of base metal and weld metal. As a result, a lower elongation occurs in the weldment ruptured after creep. Moreover, this ductility variety between welded joint and the BM can be partly elucidated in the view of high-temperature tensile behavior (engineering strain-engineering stress) at $923 \mathrm{~K}$, which are displayed in Fig. 6. The values denoting near the intersection between dashed lines and deformation curves show the engineering strain at the involved stress (200 and $220 \mathrm{MPa}$ ). It can be seen that the strain increment from 200 to $220 \mathrm{MPa}$ of the BM is around 2.5 times greater than that of weldment. The BM dramatically exhausts its ductility under a load of over $206 \mathrm{MPa}$, and thus, it shows a minimal ability to resist plastic deformation based on theories of grain-boundary void growth and matrix creep [16]. This can be attributed to the irreversible transformation in microstructure at the yield limiting, such as the occurrence of dislocation and other imperfections [17].

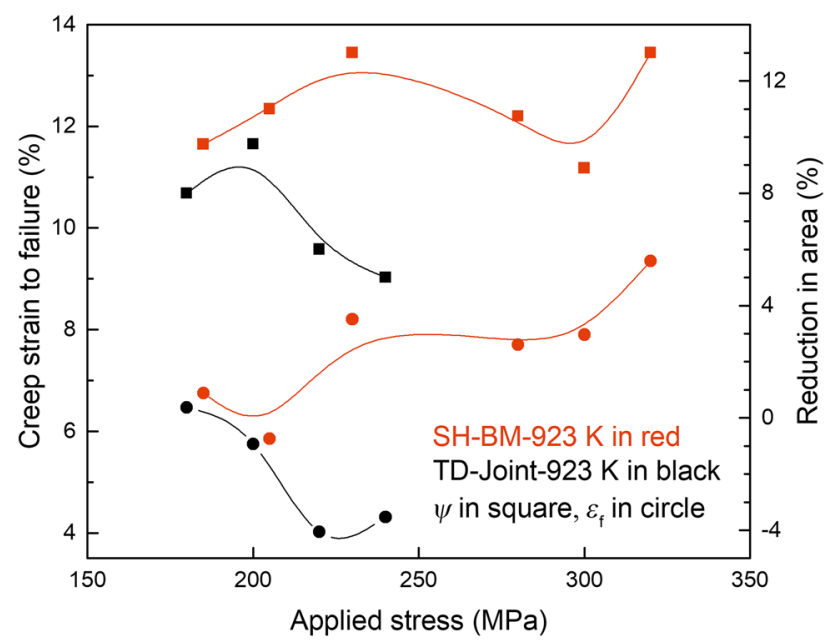

Fig. 5 Creep ductility variations of the BM and weldment at $923 \mathrm{~K}$

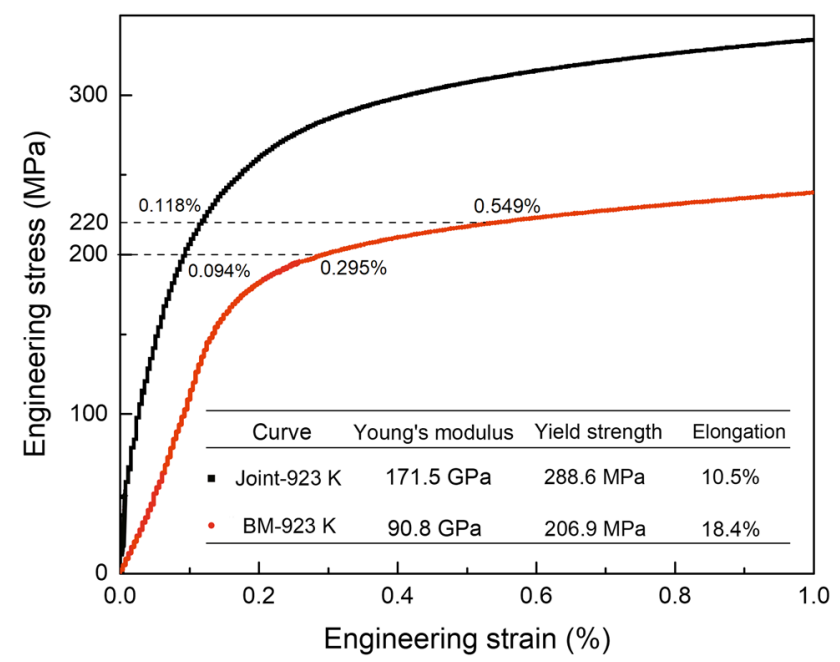

Fig. 6 Partial view of strain-stress curves for the BM and weldment at $923 \mathrm{~K}$

Generally, the law can be furthermore utilized to predict the creep life of weldments between an austenite heat-resistant steel and a nickel base weld metal when a succession of creep rupture time under different stress levels of the BM and a handful of creep life of weldments are obtained at a certain temperature.

\subsubsection{Creep Activation Energy of the Steel}

Creep activation energy for rupture $\left(Q_{1}\right)$ can be calculated by equation $t_{\mathrm{r}}=A_{1} \sigma_{a}^{-n_{1}} \exp \left(Q_{1} /(R T)\right)$, where $T$ is the absolute temperature and $R$ is the gas constant. As shown in an Arrhenius plot $\left(\ln t_{\mathrm{r}}-1 / T\right)$ in Fig. 7, the $Q_{1}$ gives values of $221-348 \mathrm{~kJ} / \mathrm{mol}$, which is suspected to be lower than the creep activation energy $(Q)$ obtained from relations based on the minimum creep rate or the steady creep rate.

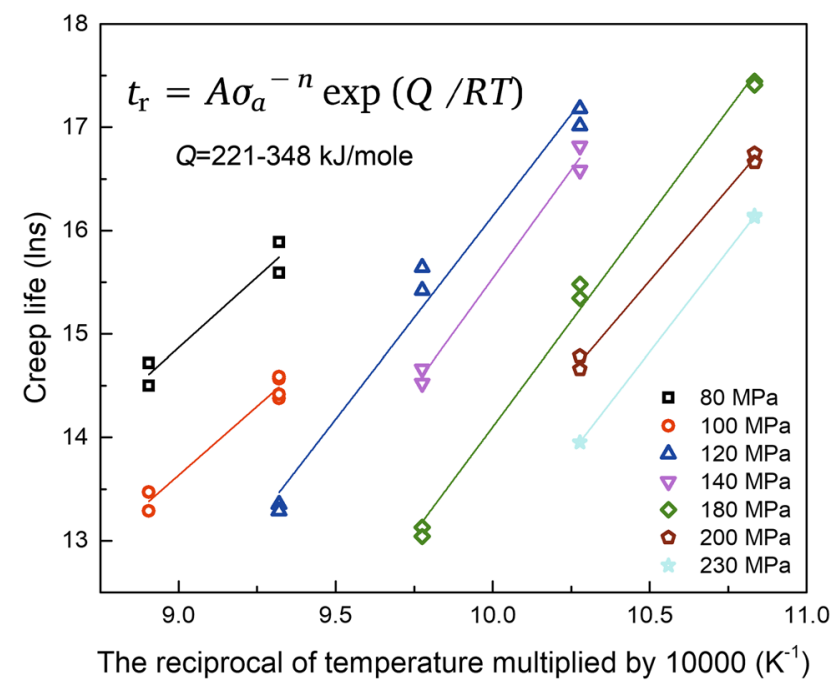

Fig. 7 Arrhenius plots of the BM at different applied stresses 
However, creep activation energy for rupture of this steel is still larger than that of the solid solution Fe-based single FCC phase alloys due to the inescapable inhibition effect of precipitates against dislocation mobile. The co-existence of three nano-sized precipitates $(M X, \mathrm{Cu}$-rich, and $\mathrm{NBCrN}$ phase) was also found in a $\mathrm{Fe}-\mathrm{Cr}-\mathrm{Ni}$ austenitic $\gamma$-matrix after $650{ }^{\circ} \mathrm{C} / 500 \mathrm{~h}$ long time aging [8]. Anyway, further research has been conducted on detailed precipitation behavior of the steel during long-term creep.

\subsection{Creep Life Assessment of $22 \mathrm{Cr} 15 \mathrm{Ni3} .5 \mathrm{CuNbN}$}

The time-temperature parametric (TTP) methods are dependent on the temperature and applied stress at which materials are exposed and the length of rupture time under the test condition [18]. The theories and development of the time-temperature parametric relationships are covered in greater depth. Three versions of such time-temperature parameters are dealt with herein, notably: Larson-Miller parameter (LMP), Manson-Haferd parameter (MHP), and Orr-Sherby-Dorn (OSDP), which have been applied with considerable success over the years [19]. Prevention of the overestimation of long-term creep rupture life, however, has been a tough challenge [20,21]. Against this background, a novel methodology was developed for analyzing creep fracture data of $9-12 \%$ chromium steels by accessing the ultimate tensile strength value and creep activation energy for rupture [10]. In this way, the latest $10^{5} \mathrm{~h}$ extrapolating strength determined from a large scale of creep tests can be predicted accurately by extrapolation of creep life measurements lasting less than $30,000 \mathrm{~h}$.

\subsubsection{Larson-Miller Parameter}

Larson and Miller revealed that their results of creep life could be collapsed into a common curve using a normalization of the form $\mathrm{LMP}=T\left(C+\lg t_{\mathrm{r}}\right)$, where $C$ is the $\mathrm{LM}$ constant. The normalization has been widely used as a phenomenology method to correlate effects of time and temperature on a range of thermally activated processes of metallic materials. As shown in Fig. 8, three master curves are plotted with different values of $C(15,17$, and 20), where the master curve with $C=17$ performs the best correlation coefficient $\left(R^{2}\right)$. Creep lives at $873 \mathrm{~K}$, however, show a slight departure from the master curve since the dynamic fracture can occur under higher stress levels. As per the master curve with $C=17$, extrapolating strength $\left(\sigma_{10^{5}}^{923}\right)$ of rupture time at $10^{5} \mathrm{~h}$ at $923 \mathrm{~K}\left(650^{\circ} \mathrm{C}\right)$ can be obtained as 148.24 MPa.

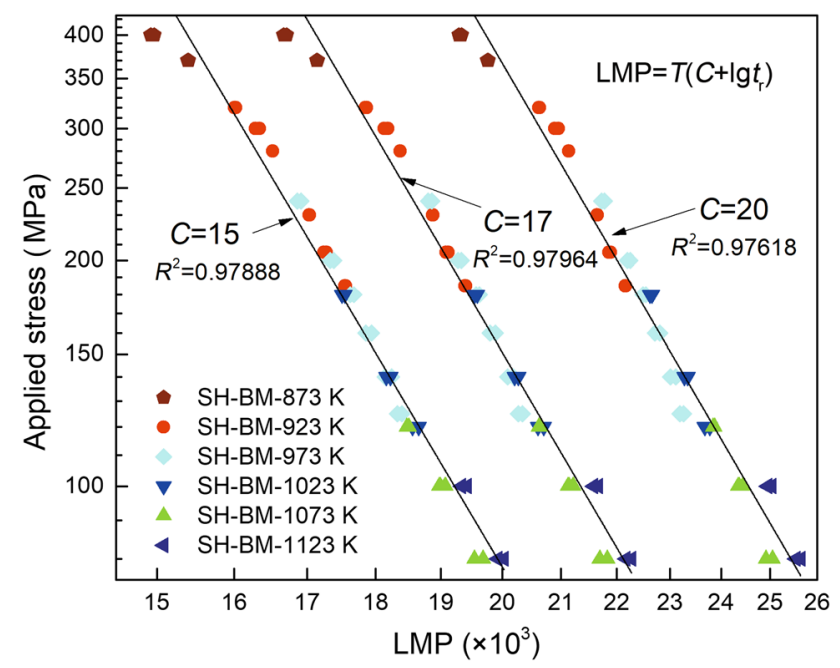

Fig. 8 Selection of Larson-Miller constant (C)

\subsubsection{Manson-Haferd Parameter}

Manson-Haferd parametric equation [22] was built by Manson and Haferd based on examination of the published creep life data for a variety of materials. A plot of this parameter against stress for a given alloy falls into a single curve with little scatter. The Manson-Haferd parametric equation can be expressed as MHP $=\frac{\lg _{\mathrm{r}}-\lg t_{\mathrm{a}}}{T-T_{\mathrm{a}}}$ or $\lg \left(t_{\mathrm{r}}\right)=$ $\left(T-T_{\mathrm{a}}\right) \cdot\left(c_{0}+c_{1} \lg \sigma+c_{2} \lg ^{2} \sigma+c_{3} \lg ^{3} \sigma\right)+\lg t_{\mathrm{a}}$, where $t_{\mathrm{a}}$ is the creep rupture time of a material at $T_{\mathrm{a}}$. According to a study on assessment of creep rupture strength for grade 91, the method is recommended in most cases by European creep collaborative committee (ECCC) [23]. Figure 9 shows the creep life (with a logarithmic coordinate) against the tested temperature under different applied stresses. The particle swarm optimization (PSO) method was used to

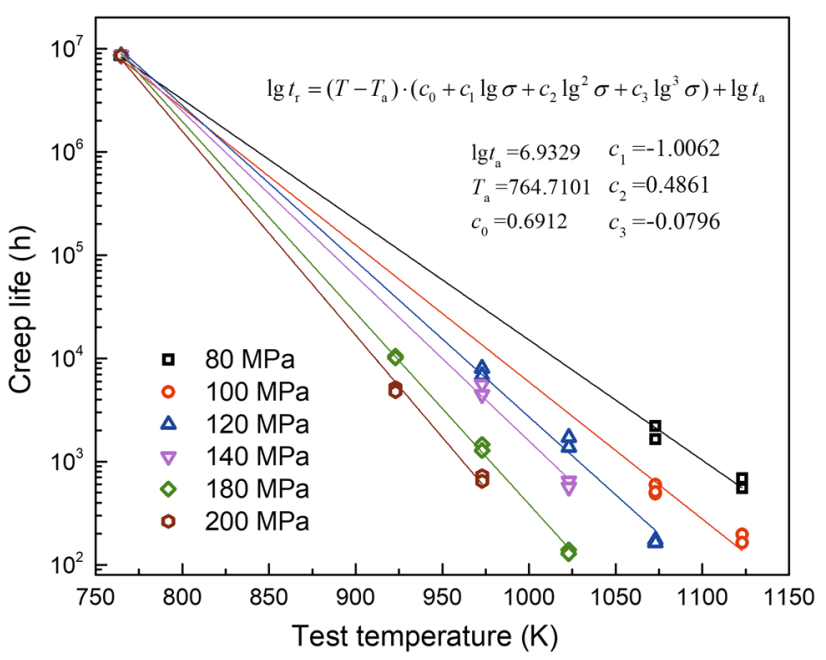

Fig. 9 Isostatic curves for $\mathrm{M}-\mathrm{H}$ method plotted with the optimal $\left(T_{\mathrm{a}}\right.$, $\left.t_{\mathrm{a}}\right)$ 
discover the point whose total distance from each isostatic line maintains the minimum value and as a consequence $\left(764.7 \mathrm{~K}, 10^{6.9} \mathrm{~h}\right)$ was selected as the optimal $\left(T_{\mathrm{a}}, t_{\mathrm{a}}\right)$. By solving isostatic lines with connected to the point of $\left(T_{\mathrm{a}}\right.$, $t_{\mathrm{a}}$ ), quantities of coefficients $c_{0}-c_{3}$ were given as annotated in Fig. 9. The master curve of MHP is illustrated in Fig. 10, and it presents a greater relevancy to tests results than the LM method. Based on the MHP master curve, the extrapolating strength of creep lifespan of $10^{5} \mathrm{~h}$ at $923 \mathrm{~K}$ can be calculated as $83.71 \mathrm{MPa}$.

\subsubsection{Orr-Sherby-Dorn Parameter}

Equation OSDP $=\ln t_{\mathrm{r}}-\frac{Q_{1}}{R T}$ was firstly proposed by Orr et al. [24], which was successfully applied to data for aluminum, titanium, nickel, niobium, molybdenum, and several characteristic high-strength commercial heat-resistant alloys. The multiregional analysis such as OSDP method is necessary for the correct evaluation of the longterm creep properties [25]. As shown in Fig. 11, the creep lifetime data are plotted in the various isothermal curves. By solving the master curve of $923 \mathrm{~K}$, the extrapolating strength of creep life of $10^{5} \mathrm{~h}$ at $923 \mathrm{~K}$ can be obtained as $119.9 \mathrm{MPa}$.

\subsubsection{Wilshire Equations}

The creep activation energy for rupture life of traditional 9-12Cr ferritic steels (grades 91, 92, and 122) often decreases in long-term creep, and the conventional TTP methods overestimate long-term rupture life of such steels, which is known as premature failure [26]. Wilshire et al. $[27,28]$ established equations via introducing creep activation energy for rupture and normalizing the applied stress through the appropriate ultimate tensile strength

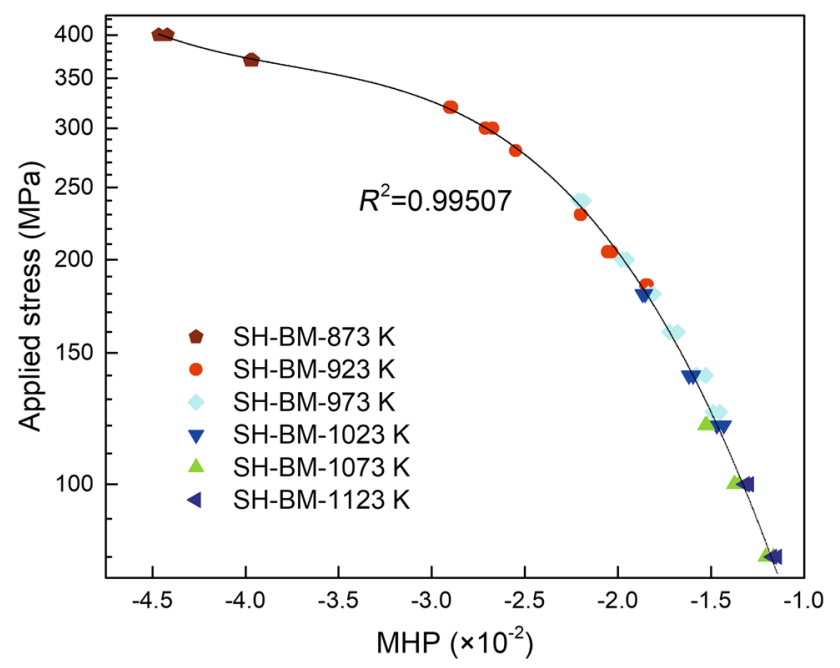

Fig. 10 Creep lifetime data and the master curve of the M-H method

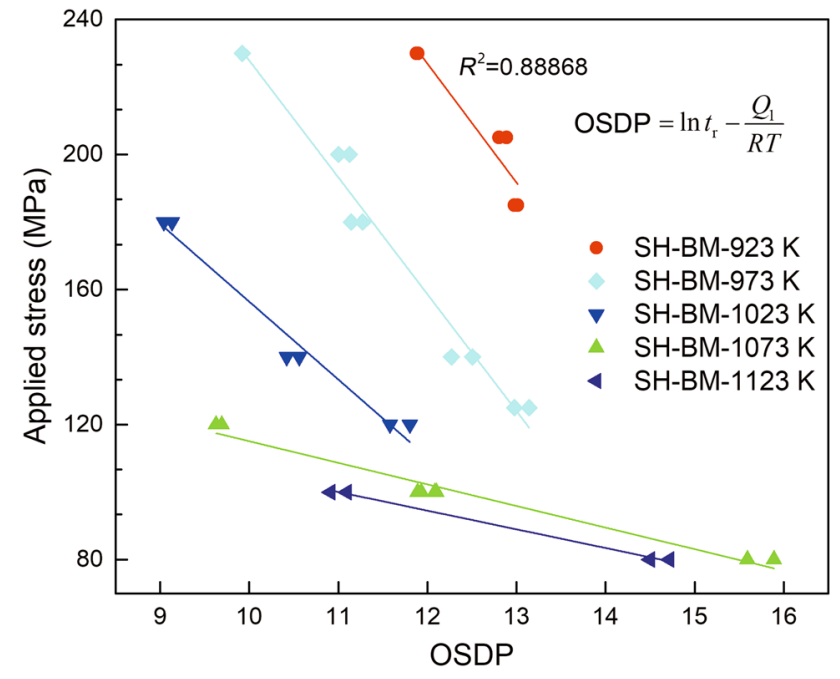

Fig. 11 Creep lifetime data and the isothermals of the OSD method

value $\left(\sigma_{\mathrm{TS}}\right)$, which can be expressed as $\frac{\sigma}{\sigma_{\mathrm{TS}}}=\exp \left[-k_{1}\left(t_{\mathrm{r}} \exp \left(\frac{Q_{1}}{R T}\right)\right)^{\mu}\right]$, where $k_{1}$ and $\mu$ are the constants of the Wilshire equation. As shown in Fig. 12, amounts of $k_{1}$ and $\mu$ can be obtained via a double natural logarithmic plot of $-\ln \frac{\sigma}{\sigma_{\mathrm{TS}}}$ versus $t_{\mathrm{r}} \exp \left(\frac{Q_{1}}{R T}\right)$ using the activation energy for lattice diffusion in the alloy steel matrixes $\left(300 \mathrm{~kJ} / \mathrm{mol}^{-1}\right)$ [10]. Substituting $10^{5} \mathrm{~h}$ and $923 \mathrm{~K}$ into Wilshire equations, extrapolating strength of the involving creep lifetime is given as $69.18 \mathrm{MPa}$.

As listed in Table 3, the calculated extrapolation strengths at $10^{5} \mathrm{~h}$ vary considerably with different data analysis methods. Hence, two classical statistical indices were used to evaluate the precision of these prediction methods. The sum of squared residuals (also known as residual sum of squares, RSS) is a principal approach to

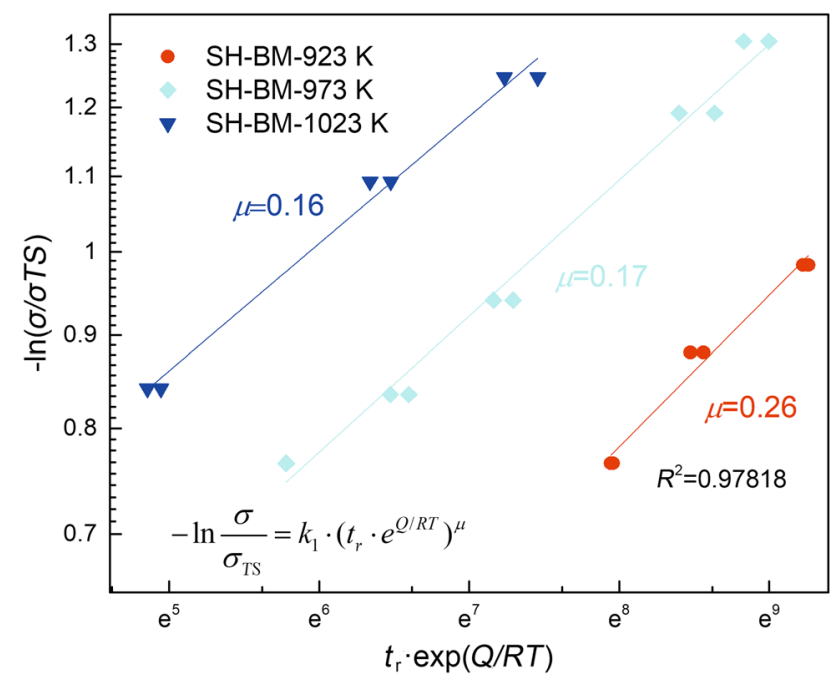

Fig. 12 Creep lifetime data and the isothermals of Wilshire's equation 
Table 3 Creep life prediction by different methods

\begin{tabular}{lcll}
\hline Methods & $\sigma_{10^{9}}^{923}(\mathrm{MPa})$ & RSS & RMS \\
\hline Power law & 132.49 & 0.0436 & 0.0222 \\
Laron-Miller & 137.12 & 0.0383 & 0.0049 \\
Manson-Herford & 83.71 & 0.0090 & 0.0138 \\
Orr-Sherby-Dorn & 119.9 & 0.0226 & 0.0364 \\
Wilshire equation & 69.18 & 0.00137 & 0.02911 \\
\hline
\end{tabular}

judge the bias of the predicted extrapolation strengths, which is defined as

$\mathrm{RSS}=\sum_{i=1}^{n}\left(\lg \sigma_{\text {pre }}-\lg \sigma_{\text {act }}\right)^{2}$,

where $\sigma_{\text {act }}$ is actual rupture stress for a given creep rupture time and $\sigma_{\text {pre }}$ is extrapolation strength for the same creep lifetime predicted by one of methods. In light of reports $[29,30]$, the root mean square (RMS) was used to estimate the precision of several TPP prediction methods, which can be expressed as RMS $=\sqrt{\frac{\sum_{i=1}^{n}\left(\lg \sigma_{\mathrm{pre}}-\lg \sigma_{\text {act }}\right)^{2}}{n}}$, where $\sigma_{\text {act }}$ is actual rupture stress for the creep lifetime longer than $2000 \mathrm{~h}$, and $\sigma_{\text {pre }}$ is extrapolation strength predicted by a certain method using the creep lifetime less than $2000 \mathrm{~h}$. It is notable that theses evaluations only focus on data at $923 \mathrm{~K}$ if the method is dependent on temperature. In addition, the critical time for RMS of Orr-Sherby-Dorn and Wilshire equations is $5000 \mathrm{~h}$ other than $2000 \mathrm{~h}$ due to deficient data.

The extrapolating strengths $\left(\sigma_{10^{5}}^{923}\right)$ are plotted in Fig. 13 with the RSS and RMS values. The power law, LM, and OSD methods give the extrapolation strengths over $100 \mathrm{MPa}$, while the MH and Wilshire equations give the

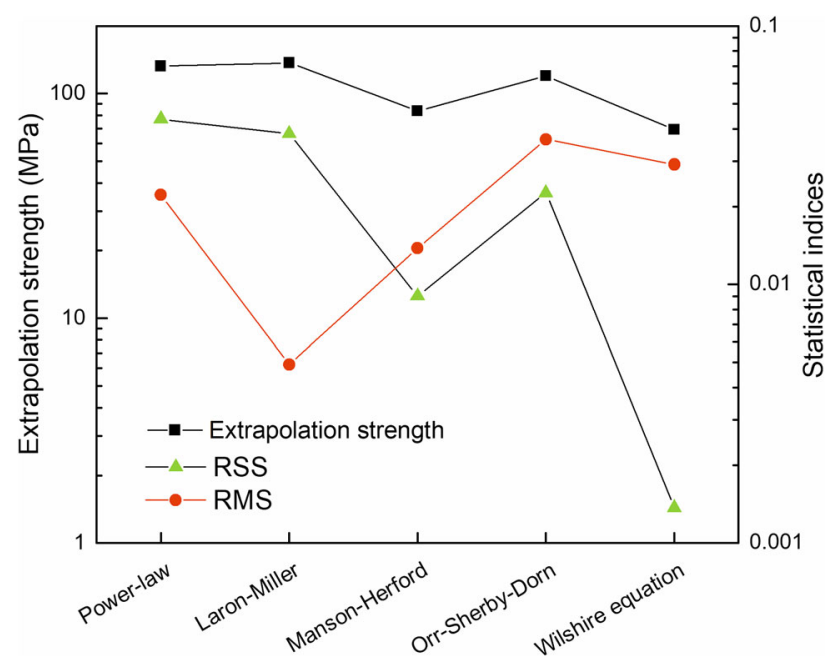

Fig. 13 Accuracy comparison for the different methods extrapolation strengths below $100 \mathrm{MPa}$. The LM method shows the smallest value of RMS, and the Wilshire equations method shows the smallest value of RSS. Anyway, the MH method performs the highest accuracy among all the methods by synthetically considering the RMS and the RSS. In this study, the prediction of $\sigma_{10^{5}}^{923}=83.71 \mathrm{MPa}$ computed by $\mathrm{MH}$ method was accepted as an optimal extrapolating strength value.

\subsubsection{Comparison with Commercial Heat-Resistant Steels}

Considering the extensive prospect of the $22 \mathrm{Cr} 15 \mathrm{Ni3} .5-$ $\mathrm{CuNbN}$, it is imperative to compare the extrapolating strength of this steel with commercial austenitic heat-resistant steels. Super304H (UNS S30432), HR3C (UNS S31042), and TP347HFG (UNS S34710) are routinely used for $600{ }^{\circ} \mathrm{C}$ USC boilers, and a large amount of these grades has been installed in boiler superheater/reheater components application. Figure 14a displays the $\log -\log$ plots between creep life versus applied stress for $22 \mathrm{Cr} 15 \mathrm{Ni} 3.5$ $\mathrm{CuNbN}$, Super304H, HR3C, and TP347HFG [31]. The comparative extrapolating strengths $\left(\sigma_{10^{5}}^{923}\right)$ predicted by power law $\left(t_{\mathrm{r}}=A_{1} \sigma_{a}^{-n_{1}}\right)$ are listed in Fig. 14a as well, which shows a decisive advantage for $22 \mathrm{Cr} 15 \mathrm{Ni} 3.5 \mathrm{CuNbN}$ than other grades at $923 \mathrm{~K}$. Meanwhile, a relatively conservative value is obtained in assessing the extrapolating strength for $22 \mathrm{Cr} 15 \mathrm{Ni} 3.5 \mathrm{CuNbN}$ by using the MansonHaferd parametric method when compared with other TPP approaches. As shown in Fig. 14b, however, the MHP extrapolating strengths for Super304H and HR3C both only fall onto the range of $60-70 \mathrm{MPa}$. In summary, $22 \mathrm{Cr} 15 \mathrm{Ni} 3.5 \mathrm{CuNbN}$ possesses an excellent creep resistance ability to become a hopeful alternative that services at temperature of $630-650{ }^{\circ} \mathrm{C}$.

\subsection{Creep Deformation and Rate Analysis of Weldment}

Creep deformation curves (creep strain-creep time) and rate curves (creep strain rate-creep time) of the present study are shown in Fig. 15a, b, respectively. The corresponding creep data are listed in Table 4. Creep rate curve of each test can be divided into primary, secondary, and tertiary creep regimes. In the primary creep regime, the creep rate decreases prominently with high temperature exposing, which is caused by work hardening caused by dislocation multiplication and interactions. Afterward, the creep rate reaches a minimum value, and the secondary creep regime appears where the work hardening effect and the recovery mechanism reach equilibrium via processes such as dislocation annihilation and rearrangement. Eventually, rapid creep deformation occurs in the tertiary stage 

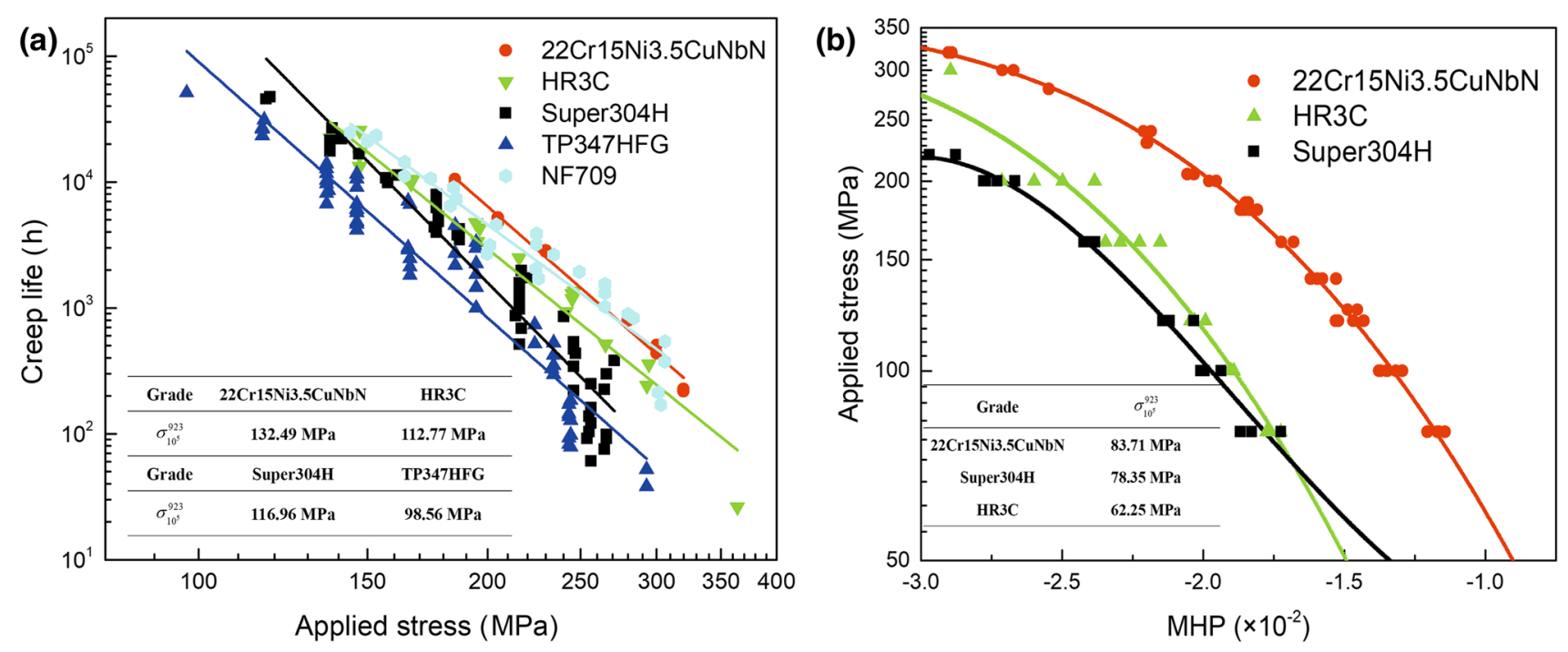

Fig. 14 Comparison of creep data at $923 \mathrm{~K}$ with other commercial heat-resistant steel
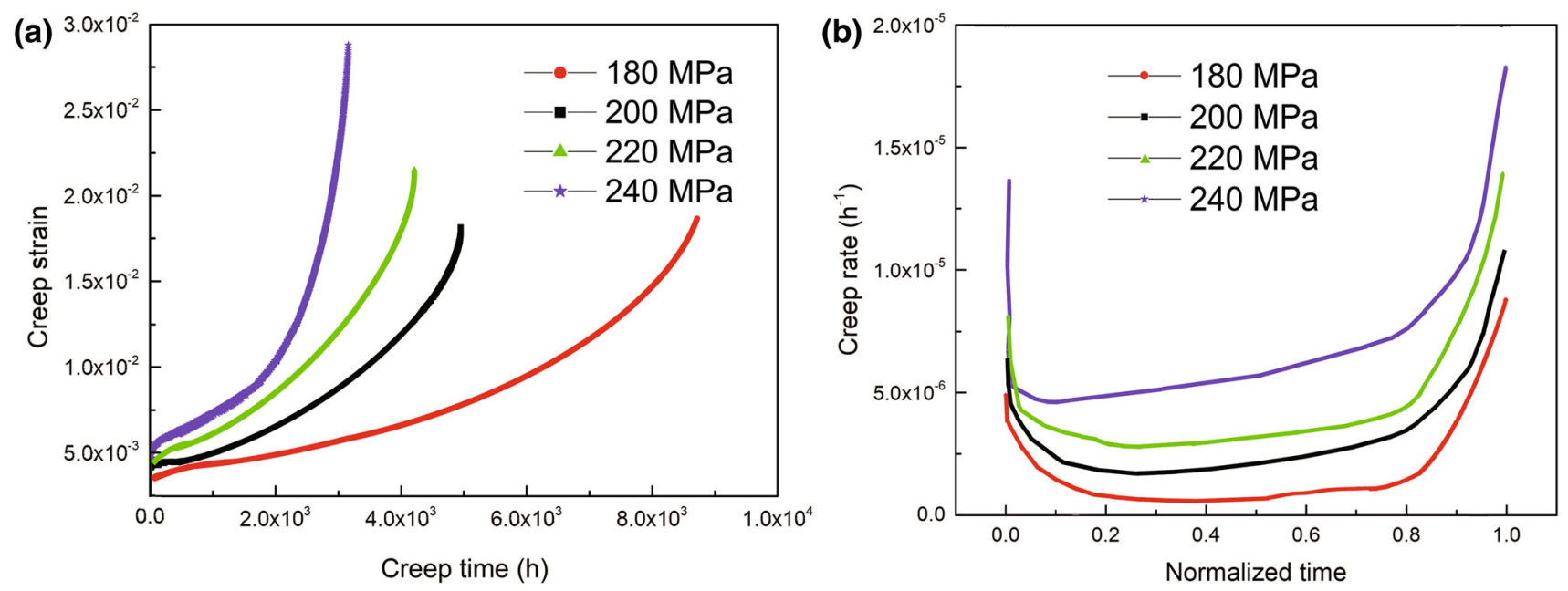

Fig. 15 Curves of a creep strain-time, $\mathbf{b}$ creep rate-normalized time under different applied stress levels

Table 4 Creep data list of welded joint in the present study

\begin{tabular}{llll}
\hline Applied stress, $\sigma_{\mathrm{a}}(\mathrm{MPa})$ & Minimum creep rate, $\dot{\varepsilon}_{\min }\left(\mathrm{h}^{-1}\right)$ & Creep life, $t_{\mathrm{r}}(\mathrm{h})$ & Creep rupture strain, $\varepsilon_{\mathrm{f}}(\%)$ \\
\hline 180 & $6.71 \mathrm{E}-07$ & 8947 & 6.47 \\
200 & $1.53 \mathrm{E}-06$ & 4949 & 5.75 \\
220 & $2.33 \mathrm{E}-06$ & 3966 & 4.63 \\
240 & $4.72 \mathrm{E}-06$ & 3144 & 3.35 \\
\hline
\end{tabular}

until fracture. The dramatic growth of creep rate with creep strain in the tertiary regime can be ascribed to reinforcement of the creep recovery processes and growth of precipitates and cavities (Table 5).

As displayed in Fig. 16a, time to onset of secondary creep $\left(t_{\mathrm{sec}}\right)$ and time to onset of tertiary creep $\left(t_{\text {tri }}\right)$ are logarithmically plotted against ruptured time $\left(t_{\mathrm{r}}\right)$. Fitting curve of time to inception of secondary creep obviously performs two types of slope, which demonstrates that the proportion of primary creep notably varies with the applied stress ranging from 180 to $240 \mathrm{MPa}$. This can be explained by introducing the effective stress theory. Effective stress 
Table 5 Creep-strength reduction factors for welded $22 \mathrm{Cr} 15 \mathrm{Ni} 3.5$ $\mathrm{CuNbN}$ tube at 923 and $973 \mathrm{~K}$

\begin{tabular}{lllll}
\hline Creep lifetime (h) & 1000 & 3000 & 5000 & 8000 \\
\hline Reduction factors at $923 \mathrm{~K}$ & 1.227 & 1.063 & 1.010 & 0.904 \\
Reduction factors at $973 \mathrm{~K}$ & 1.053 & 0.793 & 0.757 & 0.656 \\
\hline
\end{tabular}

$\left(\sigma_{\mathrm{E}}\right)$ consists of the initial effective stress $\left(\sigma_{\mathrm{E}}^{0}\right)$ and an additional increment of yield stress $\left(\sigma_{\mathrm{E}}^{\mathrm{R}}\right)$ during loading. The initial effective stress is necessary for dislocations to overcome the resistance to dislocation movement which includes the intrinsic resistance (e.g., periodic lattice resistance) and the extrinsic resistance, e.g., the phonon drag and the initial restriction of movement induced by the presence of other dislocations at the inception condition of the material. The additional increment of yield stress is the result of a change in the motion resistance due to the variation of short-range-ordering interactions of dislocations with themselves (e.g., Lomer-Cottrell sessile dislocation junctions) and with other defects, e.g., solute atoms, resulting in a change in the flow stress upon further loading [32]. A longer primary creep regime, thus, implies the emergence of a "harder" nature to resist creep.

The creep behavior is mainly dominated by the BM under applied stress of 180 and $200 \mathrm{MPa}$, while creep behavior is mainly controlled by the combined effect of the $\mathrm{BM}$ and the WM under applied stress of over $200 \mathrm{MPa}$. This phenomenon is caused by the fact that the applied stress levels of the creep tests just pass through the yield strength of BM (208 MPa), beyond which the BM depletes its ductility due to the irreversible formation of dislocation and other imperfections [33, 34]. However, time to onset of
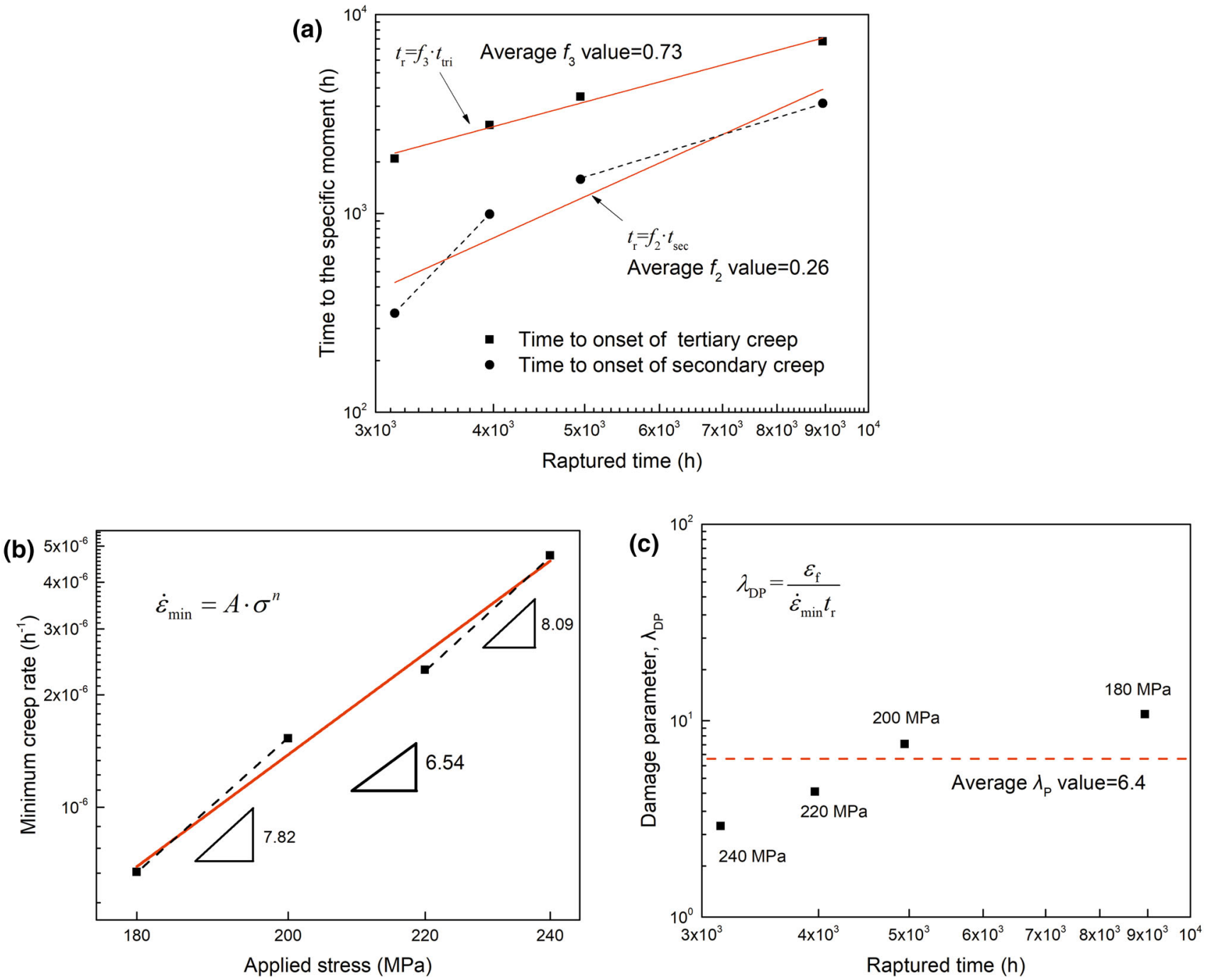

Fig. 16 Variations of a time to the specific moments versus ruptured time; $\mathbf{b}$ minimum creep rate versus applied stress; $\mathbf{c}$ damage tolerance factor versus creep ruptured time 
tertiary creep appears to be unified at 180-240 MPa, because the accumulation of creep damage toward the last creep stage would tend to reach a close degree under different stresses. These creep damage processes of the analogous grades include the formation of microvoids and microcrack, the development of subgrains, and the roughening of carbides.

As shown in Fig. 16b, a double logarithmic plot of minimum creep rate $\left(\dot{\varepsilon}_{\min }\right)$ versus applied stress was linearly fitted in the format of Norton's power law ( $\dot{\varepsilon}_{\text {min }}=A \cdot \sigma^{n}$ ) where $A$ is the pre-exponential constant and $n$ is the stress exponent of the matrix, whose value characterizes the various creep deformation mechanisms in alloys [2]. The value $n=1$ suggests the presence of Harper-Dorn creep where the dislocation density stays constant irrespective of stress and creep rate is unrelated to grain size. The stress exponent $n=3$ is recognized as class I creep controlled by the migration rate of solute atoms that attached to the mobile dislocations (solute-drag creep). A stress exponent of 5 is considered to be the dislocation climbing-controlled creep with subgrains formation, which can be frequently observed in power law breakdown (PLB) or cross slip and obstacle-controlled glide. Stress exponent $n=8$ is likewise treated as dislocation climbing-controlled creep, in which the creep microstructure keeps invariant. In the present study, creep stress exponent value of 6.54 was obtained at $923 \mathrm{~K}$, which demonstrates that the dislocation climbing-controlled mechanism occurred in the weldment during creep. However, creep stress exponent of weldment crept below $200 \mathrm{MPa}$ shows a lightly lower value than that of weldment crept at over $200 \mathrm{MPa}$. This decrease may be accredited to the different microstructure that masters the creep process under diverse stress level.

\subsection{Creep Damage Tolerance and Creep Life Reduction of Weldment}

\subsubsection{Creep Damage Tolerance Factor}

Creep damage is a concept to describe the material degradation that accelerates creep rate occurring at tertiary creep regime. Ashby and Dyson gave rise to the creep damage tolerance $\left(\lambda_{\mathrm{DP}}\right)$ toward strain concentrations for engineering alloys in relation to the theory of continuum damage mechanics, which is defined as $\lambda_{\mathrm{DP}}=\frac{\varepsilon_{\mathrm{f}}}{\dot{\varepsilon}_{\min } \cdot t_{r}}$ where $\varepsilon_{\mathrm{f}}$ is creep failure strain, $t_{\mathrm{r}}$ is creep rupture time, and $\dot{\varepsilon}_{\min }$ is minimum creep rate [35]. The magnitude of $\lambda_{\mathrm{DP}}$ commonly ranges from 1 to around 20 , and it is usually employed to classify the dominant creep damage mode in micromechanisms. A value of $\lambda_{\mathrm{DP}}=1$ is found during lower strain creep, and brittle fracture is detected without the occurrence of significant plastic deformation. Larger $\lambda_{\text {DP }}$ values allude that the alloy may undertake a strain concentration and eventually fail in ductile fracture without local cracking. A value of $\lambda_{\mathrm{DP}}$ from 1.5 to 2.5 implies that the creep damage occurs due to void growth. A $\lambda_{\text {DP }}$ of $\sim 4$ indicates that the creep damage is caused by cavity growth resulting from the combined effect of power law and diffusion creep, necking and microstructural degradation. $\mathrm{A} \lambda_{\mathrm{DP}}$ value of $\sim 5$ and above indicates damages due to decrease in dislocation density, and coarsening of precipitates and subgrain structures. As shown in Fig. 16c, the average value of $\lambda_{\mathrm{DP}}$ was observed as 6.4 in this study, which suggests that coarsening of precipitates, formation of subgrains, and the decrease in dislocation density are the dominant creep damage mechanism. Meanwhile, it is remarkable that $\lambda_{\mathrm{DP}}$ of weldment crept under 200 and $180 \mathrm{MPa}$ are higher than those of weldment crept at over $200 \mathrm{MPa}$ (and also the average value), which results from a higher creep ductility and a lower minimum creep rate. As mentioned above, under a lower stress level, the creep ductility of the weldment keeps up with that of the BM.

\subsubsection{Creep-Strength Reduction Factor}

It is known that the weld metal is not always of the same composition as the parent metal. The creep-strength reduction factor was proposed to characterize the nature of the stresses and strains in the weldments and their role in design allowances [36, 37]. Assume that the uniaxial rupture equations $t_{\mathrm{rb}}=A_{1 \mathrm{~b}} \sigma_{\mathrm{a}}^{-n_{\mathrm{lb}}}$ and $t_{\mathrm{rw}}=A_{1 \mathrm{w}} \sigma_{\mathrm{a}}^{-n_{1 \mathrm{w}}}$, where $t_{\mathrm{r}}$ is the creep rupture time and $\sigma_{\mathrm{a}}$ is the uniaxial rupture stress. The subscripts $b$ and $w$ refer to the base metal and the metal in critical part of the weldment, respectively. In the multiaxial cases, an equivalent rupture stress was postulated to calculate the structural rupture life $\sigma_{\text {rupture }}=$ $\frac{\sigma_{1}^{q / n_{1}}}{\sigma_{\mathrm{e}}^{\left(n_{1}-q\right) / n_{1}}}$ where $\sigma_{1}$ and $\sigma_{\mathrm{e}}$ are the maximum principal stress and equivalent stress, respectively, and $q$ is a material constant. Consider the cases that a welded structure with the weldment is designed at a stress $\sigma_{\mathrm{w}}$ and a corresponding parent structure of the same geometry at a stress $\sigma_{\mathrm{b}}$ in virtue of the mean diameter formula. The allowable design stress in the welded structure is reduced by a factor of $R_{\sigma}=\frac{\sigma_{\mathrm{w}}}{\sigma_{\mathrm{b}}}$, and $R_{\mathrm{t}}$ is the life reduction factor $\left(R_{\mathrm{t}}=\frac{t_{\mathrm{w}}}{t_{\mathrm{b}}}\right)$. The reduction factor in terms of the design lifetime, $t_{\mathrm{D}}$, is expressed as $R_{\sigma}=\sqrt[n_{1 \mathrm{w}}]{\frac{C_{\mathrm{w}}}{t_{\mathrm{D}}}} \cdot \sqrt[n_{1 \mathrm{~b}}]{\frac{t_{\mathrm{D}}}{C_{\mathrm{b}}}}$. It is seen from the Table 4 that the creep-strength reduction factors are decreased with increasing lifetime and temperature. Notably, a good evaluation of weldment creep-strength reduction factor relies on the availability of the creep properties of the constituent materials of the weldments. Further experimental work, especially on heat-affect zone, and 
numerical simulation taken into account the stress multiaxiality should be carried out for better understanding the creep-strength reduction in the weldment.

\subsection{Fractography Analysis}

As shown in Fig. 17, the ductile intergranular failure mode with shallow dimples in fracture planes occurs at all of the fracture surfaces of the ruptured creep specimens. Meanwhile, a tearing region can be clearly observed on each fracture surface, which is considered as an eventual plastic deformation (tearing) of the fracture procedure. This is a very common fracture surface morphology that tends to appear in heat-resistant alloys ruptured after high- temperature processing. The role played by void nucleation, growth, and coalescence is regarded as the classic micromechanism of the ductile intergranular fracture. In structural metals deformed at room temperature, the voids generally nucleate by decohesion of second phase particles or by particle fracture, and grow by plastic deformation of the surrounding matrix. Void coalescence occurs either by necking down of the matrix material between adjacent voids or by localized shearing between well separated voids, as has been described in a previous review paper $[38,39]$. Furthermore, for materials deformed at elevated temperature, grain-boundary slide, wedge-cracks, or voids grow on boundaries lying roughly normal to the tensile axis
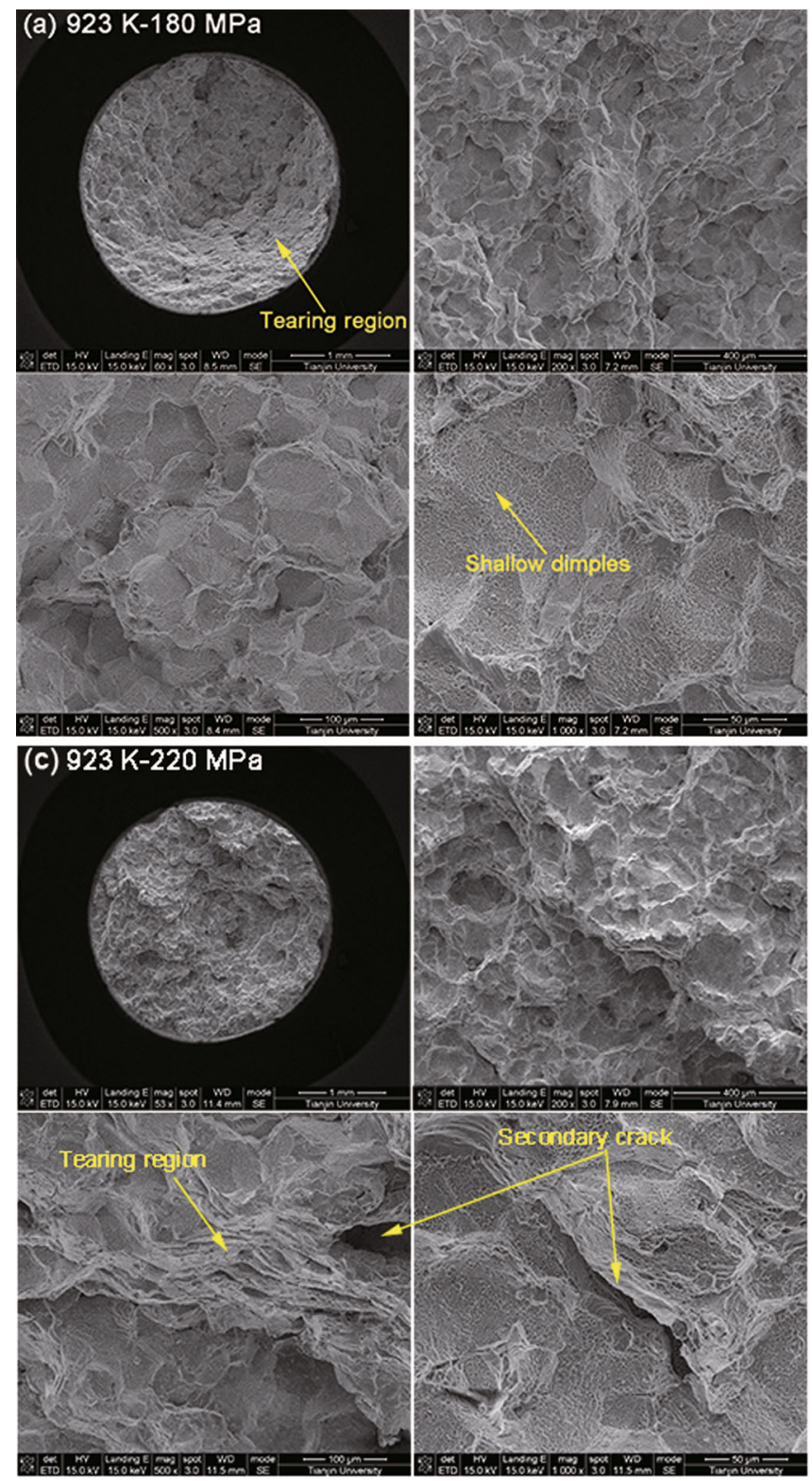
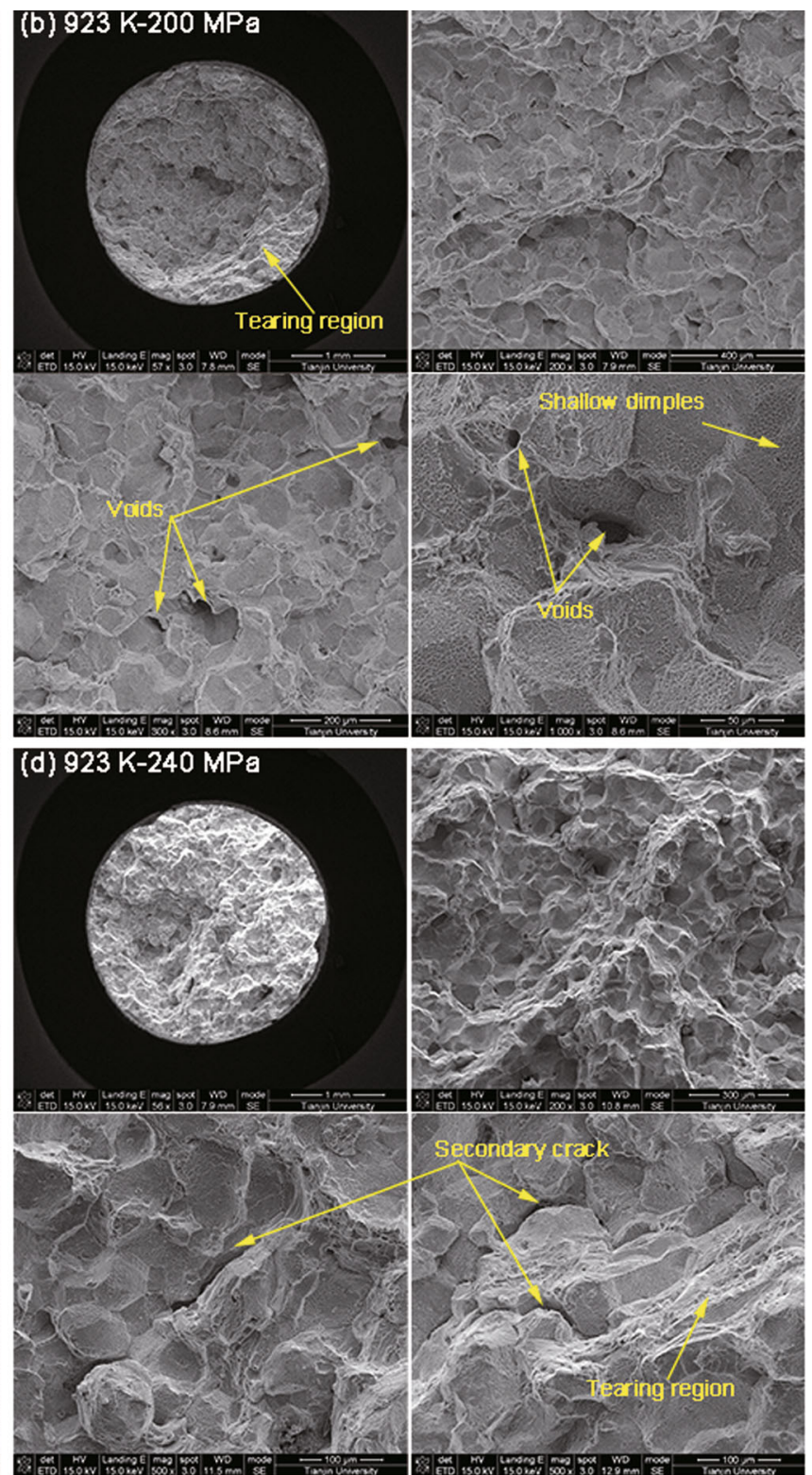

Fig. 17 Creep fractographs of specimens after creep at $923 \mathrm{~K}$ under 180-240 MPa 
are usually considered as the crack recourses, which is known as an creep-controlled intergranular fracture [40].

However, there are two main differences existing on the fracture surfaces between specimens after creep at 180-200 MPa and 220-240 MPa. For the first instance, the area proportions of tearing region in Fig. $17 \mathrm{a}, \mathrm{b}$ are apparently larger than those in Fig. 17c, d. Subsequently, the form of microdefects varies with the applied stress. For example, the fracture surface of specimen after creep at 180 MPa barely exhibits the evident voids or cracks, while the voids are the major damage existing on the fracture surface of specimen after creep at $200 \mathrm{MPa}$. The secondary cracks occur on the fracture surfaces of specimens after creep at 220 and $240 \mathrm{MPa}$, which reveals the presence of exacerbated damage. This decline in area of tearing region and the change in form of microdefects with the applied stress are mainly ascribed to effects of stress level and stress state [41]. At low stress levels, the nucleation of creep microvoids is arduous due to the insufficiency of nucleation energy. Additionally, the creep deformation of the uncavitated areas is slow enough to constrain the diffusion growth of intergranular cavities. Hence, the area proportion of the core damage zone is tiny, and the tearing zone appears to occupy most of the fracture surface. Conversely, once the applied stress increases, the cavity growth governed by vacancy diffusion on the boundary/surface is the predominant creep mechanism along with the assumption that the grains are rigid. The creep damage incubates and evolves exacerbatingly, and therefore, the damage zone prevails on the fracture surface.

\section{Conclusions}

In the present work, creep lifetime of the $22 \mathrm{Cr} 15 \mathrm{Ni} 3.5$ $\mathrm{CuNbN}$ alloy was evaluated by five approaches and compared with three commercial heat-resistant grades. The creep deformation and fracture behavior were systematically analyzed for welded joint between 22Cr15Ni3.5$\mathrm{CuNbN}$ and Inconel 617 weld metal. The following conclusions can be drawn from the results of the study.

1. The stress value at the intersection of fitting curves for creep power law between the BM and weldment is very close to the yield stress of the $\mathrm{BM}$ at $923 \mathrm{~K}$ and $973 \mathrm{~K}$, which is related to the creep ductility exhaustion model. This rule can be used to judge the creep life of weldments between an austenite heat-resistant steel and a nickel base weld metal.

2. The extrapolation strength $\sigma_{10^{5}}^{923}=83.71 \mathrm{MPa}$ calculated by Manson-Haferd parametric method was regarded as the best prediction of $22 \mathrm{Cr} 15 \mathrm{Ni} 3.5 \mathrm{CuNbN}$, which is superior to the three most common heatresistant austenite steels.

3. The creep deformation and fracture behavior of $22 \mathrm{Cr} 15 \mathrm{Ni3} .5 \mathrm{CuNbN}$ weldment perform two types of characteristics with the variation in applied stress, including: stress exponent, creep tolerance factor, and fracture surface. These changes can be explained by the effective stress and creep damage theory.

Acknowledgements This work was financially supported by the National Natural Science Foundation of China (Grant No. 51475326) and the Demonstration Project of National Marine Economic Innovation (No. BHSF2017-22). The authors also wish to acknowledge the supplier of the steel and welded joint: China Jiangsu Wujin Stainless Steel Pipe Group Co., Ltd.

\section{References}

[1] B. Xiao, L. Xu, L. Zhao, H. Jing, Y. Han, Y. Zhang, Mater. Sci. Eng. A 711, 434 (2018)

[2] Y. Zhang, H. Jing, L. Xu, L. Zhao, Y. Han, Y. Zhao, Mater. Sci. Eng. A 686, 102 (2017)

[3] Y. Zhang, H. Jing, L. Xu, L. Zhao, Y. Han, J. Liang, Mater. Charact. 130, 156 (2017)

[4] H. Yin, Y. Gao, Y. Gu, Mater. Des. 105, 66 (2016)

[5] C. Wang, Y. Guo, J. Guo, L. Zhou, Mater. Des. 88, 790 (2015)

[6] P. Yan, Z. Liu, H. Bao, Y. Weng, W. Liu, Mater. Des. 54, 874 (2014)

[7] Y. Zhang, H. Jing, L. Xu, Y. Han, L. Zhao, B. Xiao, Mater. Charact. 139, 279 (2018)

[8] X. Xie, C. Chi, H. Yu, J. Dong, M. Zhang, Y. Hu, H. Yang, C. Zhu, H. Yang, C. Zhu, Z. Cui, F. Lin, Research and development of a new austenitic heat- resisting steel SP2215 for $600-620{ }^{\circ} \mathrm{C}$ USC boiler superheater/reheater application, in Proceedings from the Eighth International Conference: Advances in Materials Technology for Fossil Power Plants, Electric Power Research Institute, Inc., Albufeira, October 11-14 (2016)

[9] J. Dean, J. Campbell, G. Aldrich-Smith, T.W. Clyne, Acta Mater. 80, 56 (2014)

[10] B. Wilshire, P.J. Scharning, Int. Mater. Rev. 53, 91 (2008)

[11] S. Goyal, K. Laha, Mater. Sci. Eng. A 615, 348 (2014)

[12] T. Shrestha, M. Basirat, I. Charit, G.P. Potirniche, K.K. Rink, Mater. Sci. Eng. A 565, 382 (2013)

[13] T. Sakthivel, S.P. Selvi, K. Laha, Mater. Sci. Eng. A 640, 61 (2015)

[14] J.A. Siefert, S.A. David, Sci. Technol. Weld. Join. 19, 271 (2014)

[15] J.A. Siefert, J.P. Shingledecker, J.N. DuPont, S.A. David, Sci. Technol. Weld. Join. 21, 397 (2016)

[16] W.M. Payten, D.W. Dean, K.U. Snowden, Mater. Sci. Eng. A 527, 1920 (2010)

[17] Y. Zhang, H. Jing, L. Xu, Y. Han, L. Zhao, D. Wang, B. Xiao, Mater. Sci. Eng. A 721, 103 (2018)

[18] J.G. Kaufman, Parametric Analyses of High-Temperature Data for Aluminum Alloys (ASM International, Portland, 2008)

[19] D. Šeruga, M. Nagode, Mater. Sci. Eng. A 528, 2804 (2011)

[20] G. Dimmler, P. Weinert, H. Cerjak, Int. J. Pres. Ves. Pip. 85, 55 (2008)

[21] H. Ghassemi Armaki, K. Maruyama, M. Yoshizawa, M. Igarashi, Mater. Sci. Eng. A 490, 66 (2008) 
[22] S. Manson, A. Haferd, Technical Report Archive \& Image Library (1953)

[23] W. Bendick, L. Cipolla, J. Gabrel, J. Hald, Int. J. Pres. Ves. Pip. 87, 304 (2010)

[24] R. Orr, O. Sherby, J. Dorn, Trans. Am. Soc. Met. 7, 113 (1953)

[25] K. Maruyama, H.G. Armaki, K. Yoshimi, Int. J. Pres. Ves. Pip. 84, 171 (2007)

[26] J.S. Lee, H.G. Armaki, K. Maruyama, T. Muraki, H. Asahi, Mater. Sci. Eng. A 428, 270 (2006)

[27] B. Wilshire, A.J. Battenbough, Mater. Sci. Eng. A 443, 156 (2007)

[28] M.T. Whittaker, B. Wilshire, Mater. Sci. Eng. A 527, 4932 (2010)

[29] R.M. Goldhoff (ed.), Development of a Standard Methodology for the Correlation and Extrapolation of Elevated Temperature Creep and Rupture Data, Volume 2: A State-of-the-Art Review, Final Report (Metal Properties Council Inc., New York, 1979)

[30] M.K. Booker (ed.), Development of a Standard Methodology for the Correlation and Extrapolation of Elevated Temperature: A Summary of a State-of-the-Art Review and a Workshop. Final Report (Metal Properties Council, Inc., New York, 1974)

[31] A. Iseda, H. Okada, H. Semba, M. Igarashi, Energy Mater. 2, 199 (2013)
[32] M.S. Pham, S.R. Holdsworth, K.G.F. Janssens, E. Mazza, Int. J. Plast. 47, 143 (2013)

[33] B. Xiao, L. Xu, L. Zhao, H. Jing, Y. Han, Mater. Sci. Eng. A 690, 104 (2017)

[34] B. Xiao, L. Xu, L. Zhao, H. Jing, Y. Han, Z. Tang, Mater. Sci. Eng. A 707, 466 (2017)

[35] M.F. Ashby, B.F. Dyson, Creep damage mechanics and micromechanisms, in Proceedings of the 6th International Conference on Fracture (ICF6), National Aeronautical Laboratory, New Delhi, 4-10 December (1984)

[36] S. Tu, R. Wu, R. Sandström, Int. J. Pres. Ves. Pip. 58, 345 (1994)

[37] S. Tu, R. Sandström, Int. J. Pres. Ves. Pip. 57, 335 (1994)

[38] A.A. Benzerga, J. Leblond, A. Needleman, V. Tvergaard, Int. J. Fract. 201, 29 (2016)

[39] L. Zhao, N. Alang, K. Nikbin, Fatigue Fract. Eng. Mater. 41, 456 (2018)

[40] M.F. Ashby, C. Gandhi, D.M.R. Taplin, in Perspectives in Creep Fracture, ed. by M.F. Ashby, L.M. Brown (Pergamon, Oxford, 1983), p. 699

[41] J. Wen, S. Tu, F. Xuan, X. Zhang, X. Gao, J. Mater. Sci. Technol. 32, 695 (2016) 